\title{
Coupling time-lapse ground penetrating radar surveys and infiltration experiments to characterize two types of non-uniform flow
}

Simone Di Prima a,b,c,*, Vittoria Giannini a,b, Ludmila Ribeiro Roder d,e, Filippo Giadrossich a,b, Laurent Lassabatere c, Ryan D. Stewart ${ }^{\mathrm{f}}$, Majdi R. Abou Najm s, Vittorio Longo h, Sergio Campus a, Thierry Winiarski c, Rafael Angulo-Jaramillo c, Antonio del Campo i, Giorgio Capello i, Marcella Biddoccu j, Pier Paolo Roggero a,b and Mario Pirastru a,b

${ }^{a}$ Department of Agricultural Sciences, University of Sassari, Viale Italia, 39A, 07100 Sassari, Italy.

${ }^{\mathrm{b}}$ Desertification Research Center, University of Sassari, Viale Italia, 39, 07100 Sassari, Italy.

${ }^{\mathrm{c}}$ Univ Lyon, Université Claude Bernard Lyon 1, CNRS, ENTPE, UMR5023 LEHNA, Vaulx-en-Velin, France

${ }^{\mathrm{d}}$ Department of Architecture, Design and Urban planning, University of Sassari, Via Piandanna, 4, 07100 Sassari, Italy.

e School of Agriculture, São Paulo State University (UNESP), Fazenda Experimental Lageado, 18610-034 Botucatu, SP, Brazil.

${ }^{\mathrm{f}}$ School of Plant and Environmental Sciences, Virginia Polytechnic Institute and State University, Blacksburg, VA, United State

${ }^{\mathrm{g}}$ Department of Land, Air and Water Resources, University of California, Davis, CA 95616, United States.

${ }^{\text {h }}$ Department of Chemistry and Pharmacy, University of Sassari, Via Piandanna 4, 07100 Sassari, Italy.

i Research Group in Forest Science and Technology (Re-ForeST), Universitat Politècnica de València, Camí de Vera, E-46022 València, Spain.

${ }^{\mathrm{j}}$ Institute of Sciences and Technologies for Sustainable Energy and Mobility (STEMS), National Research Council of Italy, 10135 Torino, Strada delle Cacce, 73 , Italy.

* Corresponding Author. E-mail: sdiprima@uniss.it

\section{Graphical abstract}

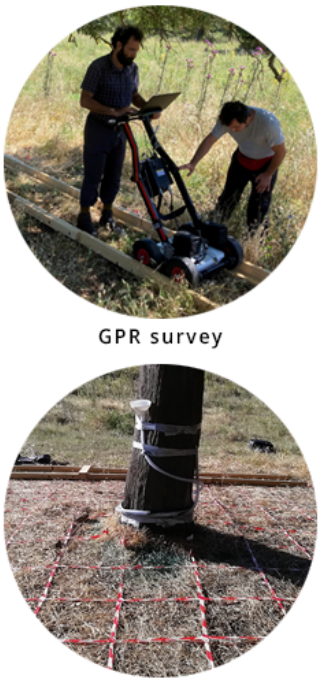

Artificial stemflow experiment

\section{SITE 1}

Time-lapse GPR surveys in conjunction with an artificial stemflow experiment

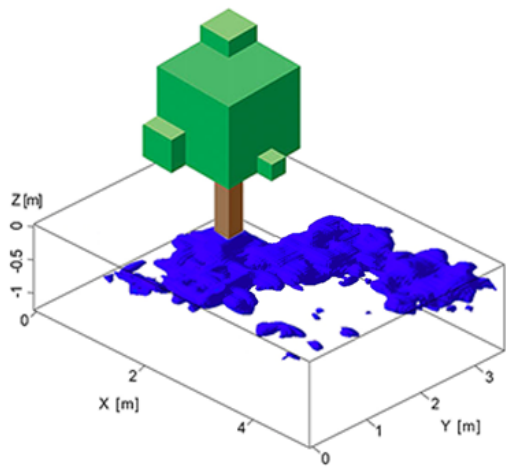

Evidence of stemflow-induced preferential flow paths along coarse roots

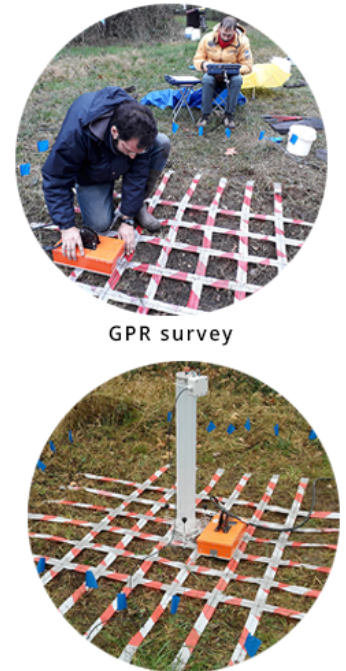

Ponding infiltration experiment
SITE 2

Time-lapse GPR surveys in conjunction with a ponding infiltration experiment

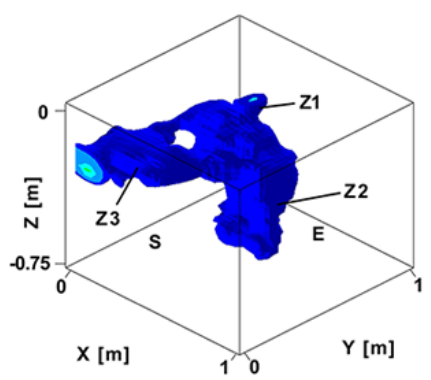

Evidence of lateral flow and preferential flow paths into a layered soil

\section{Abstract}

Understanding linkages between heterogeneous soil structures and non-uniform flow is fundamental for interpreting infiltration processes and improving hydrological simulations. Here, we utilized ground-penetrating radar (GPR) as a non-invasive technique to investigate those linkages and to complement current traditional methods that are labor-intensive, invasive, and nonrepeatable. We combined time-lapse GPR surveys with different types of infiltration experiments to create three-dimensional (3D) diagrams of the wetting dynamics. We carried out the GPR surveys and validated them with in situ observations, independent measurements and field excavations at two experimental sites. Those sites were selected to represent different mechanisms that generate non-uniform flow: (1) preferential water infiltration initiated by tree trunk and root systems; and (2) lateral subsurface flow due to soil layering. Results revealed links between different types of soil heterogeneity and non-uniform flow. The first experimental site provided evidence of root-induced preferential flow paths along coarse roots, emphasizing the important role of coarse roots in facilitating preferential water movement through the subsurface. The second experimental site showed that water infiltrated through the restrictive layer mainly following the plant root system. The presented approach offers a non-invasive, repeatable and accurate way to detect non-uniform flow.

Keywords: GPR, water infiltration, soil layers, stemflow, preferential flow. 


\section{Introduction}

Infiltration models typically include the assumptions that the sampled porous medium is rigid, homogeneous, isotropic, and has a uniform water content before the experiment (Angulo-Jaramillo et al., 2016). However, these conditions are more the exception than the rule, and for structured and other heterogeneous soils, water generally moves non-uniformly, leading to spatially irregular wetting of the soil profile (Abou Najm et al., 2019; Gerke, 2006). Different types of soil heterogeneity (e.g., water-repellent or sealed soils, multiporosity and multi-permeability systems, porous media possessing regions with distinct particle types or sizes) can induce non-uniform and preferential flow phenomena (e.g., Lassabatere et al., 2019). Investigating the linkages between heterogeneous soil structures and non-uniform flow is a prerequisite for the correct interpretation of infiltration processes and for related eco-hydrological simulations.

A number of methods have been proposed to investigate sources of heterogeneity in the subsurface, though most involve invasive and non-repeatable procedures. For instance, dyestaining is often used to reveal non-uniform flow patterns (e.g., Gerke et al., 2015; Kodešová et al., 2012). Similarly, hardening substances (e.g., liquid latex; Abou Najm et al., 2010) have been used to better characterize the size and connectivity of dominant flow paths. However, these approaches are invasive as they require excavation for the direct observation of disturbed soil profiles. A non-destructive variation of these methods uses non-Newtonian fluids (e.g., guar gum) to determine the volume of surface-connected macropores (Stewart et al., 2014) or predict the pore structure and estimate macropores vs. micropores in soils (Abou Najm and Atallah, 2016; Atallah and Abou Najm, 2019; Basset et al., 2019; Hauswirth et al., 2019). Whether destructive or not, results from those methods do not provide direct and time-variable visualization of the extent and degree of wetting that can occur from macropore structures. Those methods also do not allow to visualize other types of non-uniform flow, such as funneling that can occur along interfaces between dissimilar materials (Ben Slimene et al., 2017).

Different geophysical techniques, such as groundpenetrating radar (GPR), electrical resistivity tomography (ERT), and electromagnetic induction (EMI), have gained popularity as non-invasive techniques for investigating water infiltration into the soil (Fan et al., 2020). Among them, timelapse GPR surveys have been used at different spatial and temporal scales to gain insight on the linkages between heterogeneous soil structures and non-uniform flow (e.g., Gormally et al., 2011). With this approach, differenced twodimensional (2D) profiles of the subsurface (radargrams or Bscans) are obtained from pre- and post-wetting 2D survey lines (Birken and Versteeg, 2000). These differenced radargrams allow the user to detect variations of the dielectric contrast due to the water flow (Truss et al., 2007). In comparison to 2D acquisitions, three-dimensional (3D) GPR surveys can increase spatial resolution (Fan et al., 2020), and allow the user to investigate the shape and distribution of the wetting zones, thus improving the comprehensive understanding of water dynamics in the subsurface (Di Prima et al., 2020). However, only a few investigations have been carried out at small spatial scales (e.g., Di Prima et al., 2020; Truss et al., 2007) as obtaining precise 3D imaging of soil wetting requires additional efforts when working in the field, such as maintaining high accuracy in GPR position during the repeated surveys (Allroggen et al., 2015), and when treating the data (Fan et al., 2020).

In this investigation, we combined time-lapse GPR surveys with different types of infiltration experiments to gain insight on water dynamics at two experimental sites located in Sardinia (Italy) and Lyon (France). The sites were chosen to represent two different mechanisms that lead to the establishment of nonuniform flow. At the Italian site, we used time-lapse GPR to investigate how water infiltration from stemflow is influenced by tree and shrub root systems. At the French site, we examined lateral subsurface flow due to soil layering, and then compared the GPR survey with the 3D mapping of penetration resistance. This strategy was aimed to accurately describe soil layering and its effects on infiltration processes, while attempting to minimize soil disturbance as much as possible.

\section{Material and methods}

\subsection{Berchidda site}

\subsubsection{Experimental design and time-lapse GPR surveys}

The Berchidda site $\left(40^{\circ} 48^{\prime} 57.28^{\prime \prime} \mathrm{N}, 9^{\circ} 17^{\prime} 33.09^{\prime \prime} \mathrm{E}\right)$ is a Mediterranean open woodland system with scattered evergreen oak trees (Quercus suber L. and Quercus ilex L.), located in the long-term observatory of Berchidda-Monti (NE Sardinia, Italy). The site is representative of agro-silvo-pastoral systems widespread in the Mediterranean basin, in particular in the Iberian Peninsula (Lozano-Parra et al., 2015). The mean annual rainfall is $632 \mathrm{~mm}$, of which $70 \%$ occurs during October to May. The mean annual temperature is $14.2{ }^{\circ} \mathrm{C}$ (Seddaiu et al., 2018). According to the USDA standards, the soil of the upper horizon was classified as sandy loam (Typic Dystroxerept). The natural potential vegetation is mainly represented by cork oak forests referable to Violo dehnhardtii-Quercetum suberis association (Bacchetta et al., 2004).

We established a GPR grid $(3.5 \mathrm{~m} \times 5 \mathrm{~m}$, with a local slope of $\left.10.3^{\circ}\right)$, consisting of ten lateral $(\mathrm{Y} 0, \mathrm{Y} 0.5, \mathrm{Y} 1, \mathrm{Y} 1.5 \mathrm{~A}, \mathrm{Y} 1.5 \mathrm{~B}, \mathrm{Y} 2 \mathrm{~A}$, $\mathrm{Y} 2 \mathrm{~B}, \mathrm{Y} 2.5, \mathrm{Y} 3, \mathrm{Y} 3.5 \mathrm{~m})$ and thirteen longitudinal $(\mathrm{X} 0, \mathrm{X} 0.5, \mathrm{X} 1$, X1.5A, X1.5B, X2A, X2B, X2.5, X3, X3.5, X4, X4.5, X5 m) parallel survey lines using white/red signaling tape (Fig. 1a). The lateral lines were downslope-oriented. The grid was placed around a Quercus suber L. tree following the sampling scheme reported in Fig. 1c. A total of 46 (two GPR surveys $\times 23$ survey lines) radargrams were collected by moving the antenna on a sevenmeter-long wooden track (Fig. 1b) that was placed on each survey line just before the GPR survey in order to ensure a high re-positioning accuracy and minimizing possible geometrical mismatch between repeated GPR surveys (Allroggen et al., 2015). The position of the wooden track on each survey line was previously established using metal pegs that remained in situ while the track was moved from one survey line to the subsequent one. The survey lines that crossed the trunk of the tree were split in two parts: from the grid borders to the trunk (Y1.5A, Y2A, X1.5A, X2A), and then from the trunk to the opposite grid borders (Y1.5B, Y2B, X1.5B, X2B).

For the GPR surveys, we used an IDS (Ingegneria Dei Sistemi S.p.A.) Ris Hi Mod v. 1.0 system with a $900-\mathrm{MHz}$ antenna mounted on a GPR cart. The data were acquired using the wheel mode, which allowed us to measure the distance 

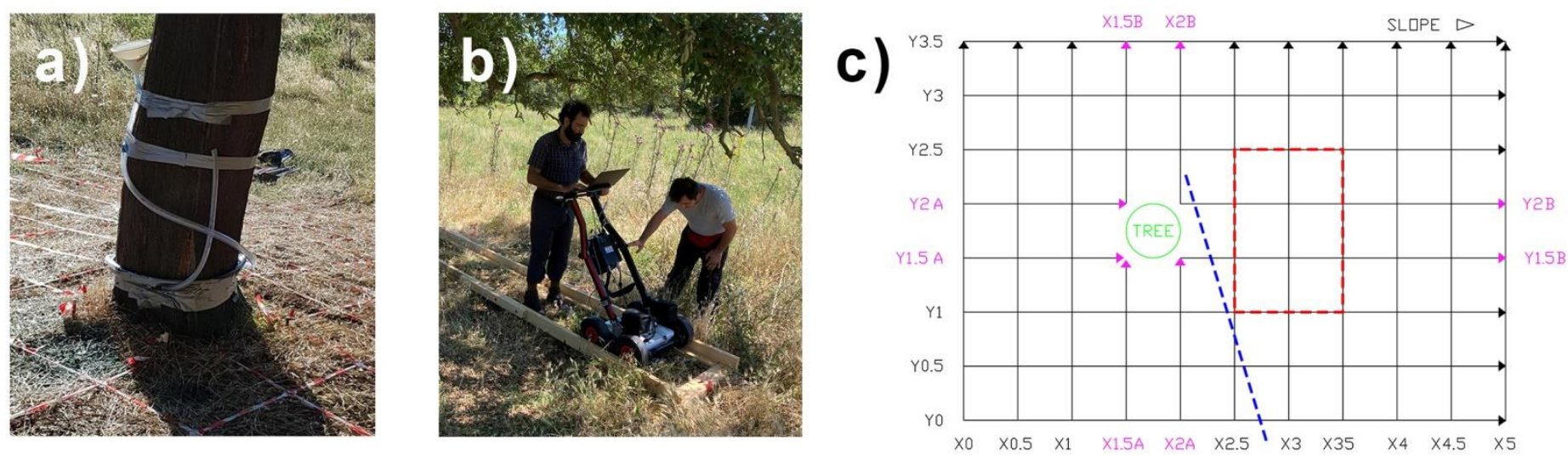

d)

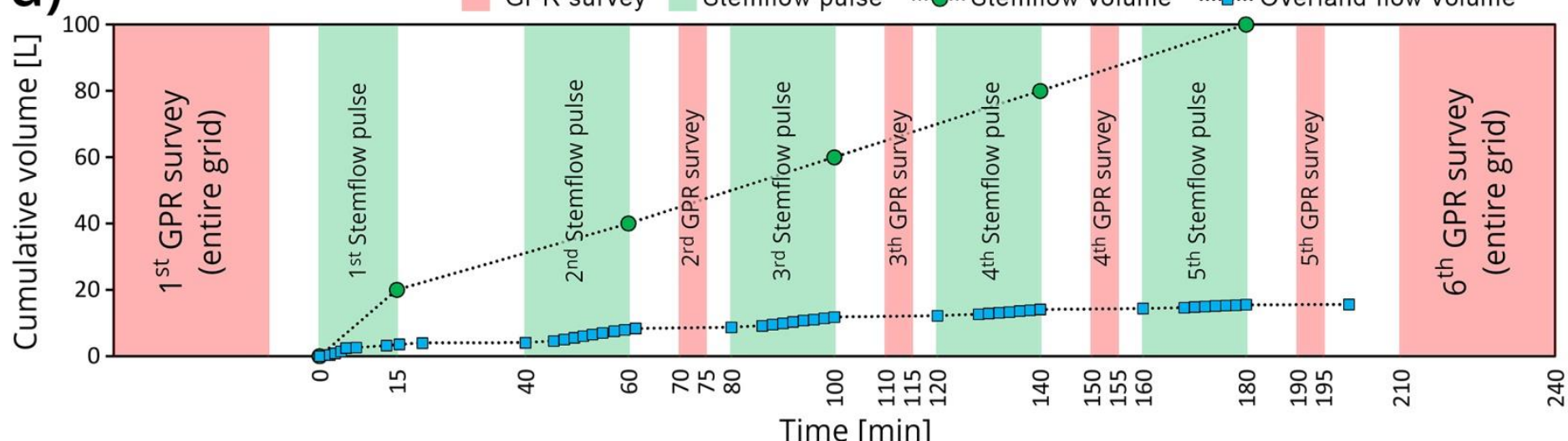

Fig. 1. Experimental setup at the Berchidda site. (a): Rubber pipe connected to a plastic funnel and positioned around the trunk tree at $0.2 \mathrm{~m}$ from the soil surface and used to apply the solution of brilliant blue dye. (b): Wooden track used to ensure a high re-positioning accuracy and minimizing possible geometrical mismatch between repeated GPR surveys. (c): Scheme of the GPR survey $(3.5 \mathrm{~m} \times 5 \mathrm{~m})$, consisting of ten lateral (Y0-Y3.5 m) and thirteen longitudinal (X0-X5 m) parallel survey lines with $0.5 \mathrm{~m}$ intervals between them. The blue dashed line illustrates the position of the $\mathrm{v}$-shaped plastic channel used to collect the overland flow. The red dashed line illustrates the position of the trench. (d): Timeline of the repeated GPR surveys and stemflow pulses. The collected overland flow volumes are also reported. (For interpretation of the references to color in this figure legend, the reader is referred to the web version of this article.)

traveled through a survey wheel equipped with a position sensor. We carried out two GPR surveys on the full grid just before and then 3.5 hours after the beginning (30 min after the end) of an artificial stemflow experiment carried out using the procedure detailed in the next section (Fig. 1d). During the artificial stemflow experiment, four additional GPR surveys were performed on three vertical survey lines at $\mathrm{X}=3,4$ and 5 $\mathrm{m}$ after 70, 110, 150 and $190 \mathrm{~min}$ the beginning of the experiment, for an additional total of 12 radargrams (4 GPR surveys $\times 3$ survey lines). These acquisitions were aimed at providing real-time monitoring of subsurface flow process along coarse roots. Finally, a $1 \mathrm{~m} \times 1.5 \mathrm{~m} \times 0.5 \mathrm{~m}(\mathrm{XYZ})$ trench (Fig. 1c, red dashed line) was carefully excavated with hand tools to remove soil and detect root locations as well as the size and areas of infiltration and preferential pathways on the soil profile.

\subsubsection{Artificial stemflow experiment}

The simulated stemflow event carried out at the Berchidda site was used to provide evidence of root-induced preferential flow. To set up the experiment, we followed the procedure described in Guo et al. (2020). We applied $100 \mathrm{~L}$ of brilliant blue dye (E133) solution $\left(1 \mathrm{~g} \mathrm{~L}^{-1}\right)$ on the tree trunk. The stemflow volume of $100 \mathrm{~L}$ corresponded to the expected volume of water collected by the tree crown for a rainfall event of $38.3 \mathrm{~mm}$, considering its crown collection area $\left(201 \mathrm{~m}^{2}\right)$ and a $1.3 \%$ conversion rate of rainfall to stemflow. This last value was suggested by de Almeida and Riekerk (1990) for a similar scattered cork oak trees system in Portugal. For context, daily precipitation values of more than $80 \mathrm{~mm}$ have been reported by the Regional Environmental Protection Authority of Sardinia Region (ARPA; www.sar.sardegna.it) at the nearby meteorological station of Tempio Pausania $\left(40^{\circ} 54^{\prime} 00^{\prime \prime} \mathrm{N}\right.$, $\left.9^{\circ} 06^{\prime} 02^{\prime \prime} \mathrm{E}\right)$.

The solution application was carried out using a rubber pipe with a 1-mm-diameter hole every $50 \mathrm{~mm}$. The pipe was connected to a plastic funnel and positioned around the trunk tree at $0.2 \mathrm{~m}$ from the soil surface (Fig. 1a). The experiment started after the first GPR survey when the first $20 \mathrm{~L}$ of solution were poured into the funnel (Fig. 1d). This first volume application lasted $15 \mathrm{~min}$. Another four volumes, each of $20 \mathrm{~L}$, were poured into the funnel after 40, 80, 120 and $160 \mathrm{~min}$ from the beginning of the experiment with a rate of $1 \mathrm{~L} \mathrm{~min}{ }^{-1}$. The volumes applications were alternated by the execution of four additional GPR surveys, which were carried out 70, 110, 150 and $190 \mathrm{~min}$ from the beginning of the experiment (Fig. 1d) on three vertical survey lines at 3,4 and $5 \mathrm{~m}$ (Fig. 1c). Overland flow was collected by a small v-shaped plastic channel placed into a groove previously scraped on the downhill side of the tree (Fig. 1c, blue dashed line). The collected volumes were measured by graduated beakers. A final GPR survey was carried out on the entire grid $30 \mathrm{~min}$ after the last volume application. 

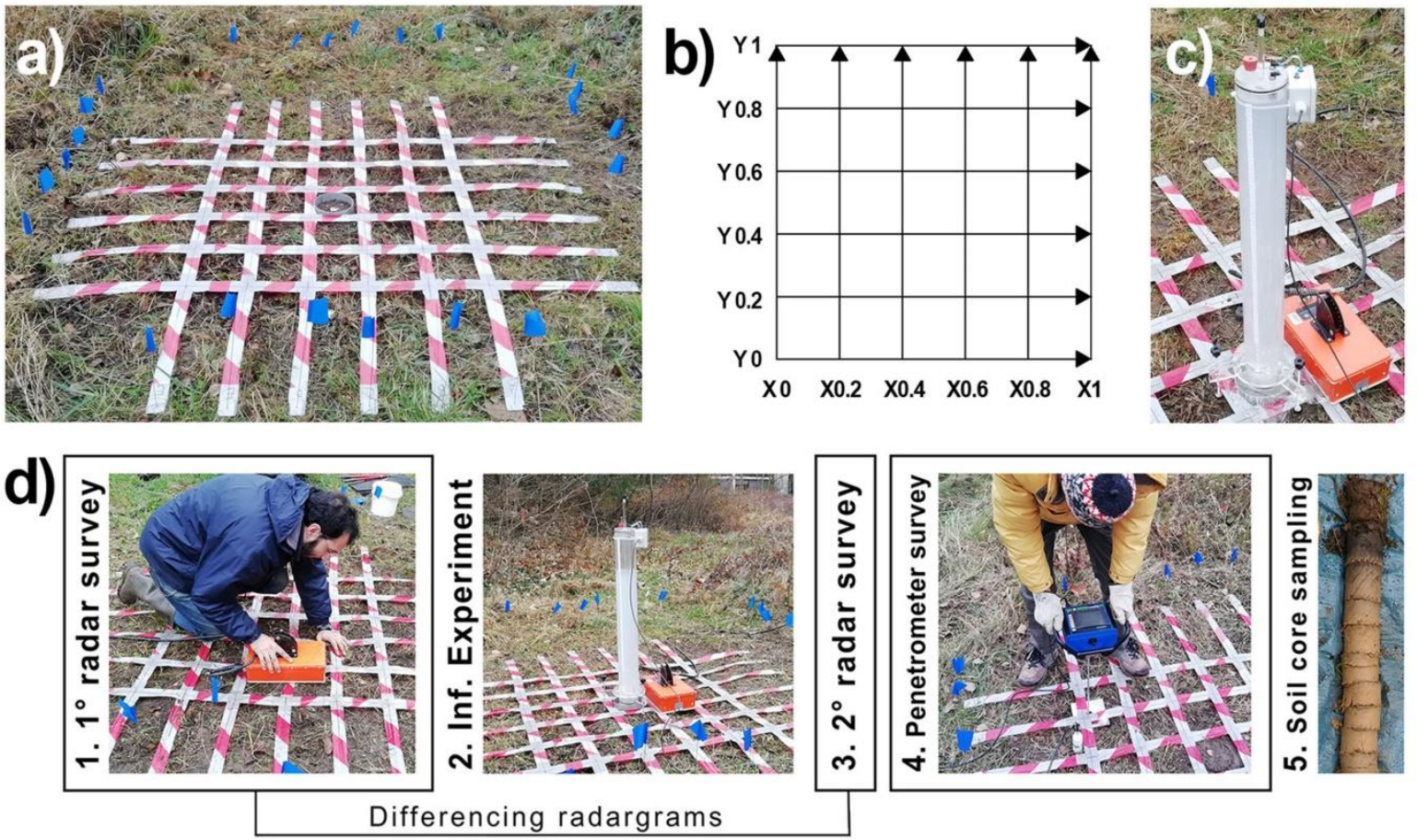

Fig. 2. Experimental setup at the Doua site. (a): GPR grid. (b): Scheme of the GPR survey $(1 \times 1 \mathrm{~m})$, consisting of six horizontal (Y0-Y1 m) and six vertical (X0-X1 m) parallel survey lines with $0.2 \mathrm{~m}$ intervals between them. (c): Automated single-ring infiltrometer proposed by Concialdi et al. (2020). (d): Flowchart illustrating the procedure to obtain the $3 \mathrm{D}$ diagrams of the wetting zone from pre- and post-wetting ground-penetrating radar surveys and the resistance penetrometer measurements at the Doua site.

\subsection{Doua site}

\subsubsection{Experimental design and time-lapse GPR surveys}

The Doua field site $\left(45^{\circ} 46^{\prime} 48^{\prime \prime} \mathrm{N}, 4^{\circ} 52^{\prime} 6.8^{\prime \prime} \mathrm{E}\right)$ was located within the La Doua scientific campus in the municipality of Villeurbanne (France). The sampled area was an open-air flume colonized by ray grass and sparse shrub plants, with a $0.2-\mathrm{m}$ thick upper coarse-textured layer with abundant gravel, under which lay a dense mineral horizon acting as restrictive layer. The GPR survey was carried out using a GSSI (Geophysical Survey System Inc., Salem, NH) SIR 3000 system with a 900$\mathrm{MHz}$ antenna. A GPR grid $(1 \mathrm{~m} \times 1 \mathrm{~m})$, consisting of six horizontal ( $\mathrm{Y} 0-\mathrm{Y} 1 \mathrm{~m})$ and six vertical $(\mathrm{X} 0-\mathrm{X} 1 \mathrm{~m})$ parallel survey lines with $0.2 \mathrm{~m}$ intervals between them, was established using white/red signaling tape (Fig. 2a and b). The vertical lines (Y0$\mathrm{Y} 1)$ were oriented along the north-south axis. In the center of the grid, a ponding infiltration test was conducted (Fig. $2 \mathrm{~d}$, step 2; see section 2.2.3). Two GPR surveys were carried out just before (Fig. 2d, step 1) and then 20 min after (Fig. 2d, step 3) the infiltration test. A total of 24 ( 2 GPR surveys $\times 12$ survey lines) radargrams were collected in time mode by moving the antenna along the survey lines and recording the markers position along the survey line intersections.

In contrast to the first site, which was dedicated to the study of the effect of coarse roots on flow pattern, the second site was used to detect lateral subsurface flow above the layer interface along with deeper preferential flow associated with smaller roots, such as those of the shrubs.

\subsubsection{Penetration resistance measurements}

Soil penetration resistance was measured at each of the 36 intersection points of the grid using an electronic hand-pushed cone penetrometer (Penetrologger, Eijkelkamp, the Netherlands). These measurements were aimed to highlight contrasting penetration resistance characteristics between different soil horizons. The cone used for the tests had a $30^{\circ}$ angle with a base area of $1 \mathrm{~cm}^{2}$. For each measurement, the driving shaft of the Penetrologger was placed at an intersection point of the grid (Fig. 2d, Step 4), and inserted into the soil at a constant speed of $2 \mathrm{~cm} \mathrm{~s}^{-1}$ to a depth of $0.8 \mathrm{~m}$. The insertion was carried out maintaining a gradient less than $3.5^{\circ}$ from the vertical position. The penetration depth was measured using an ultrasonic sensor with $1 \mathrm{~cm}$ resolution. Then, an auger was used to extract a $0.69-\mathrm{m}$-depth soil core for direct observation of soil layering (Fig. 2d, Step 5). Lastly, 24 undisturbed soil cores ( 100 $\mathrm{cm}^{3}$ ) were collected in the proximity of the sampled grid at different depths from 0 to $0.5 \mathrm{~m}$ to determine soil bulk densities and the associated initial soil water contents via the gravimetric method (Table 1). Bulk density and soil water content data were checked for normality using the Shapiro-Wilk test and for the equality of variance using Levene test, and ANOVA was

Table 1. Bulk density (BD; $\left.\mathrm{g} \mathrm{cm}^{-3}\right)$ and initial soil water content $\left(\mathrm{SWC} ; \mathrm{m}^{3} \mathrm{~m}^{-3}\right)$ values measured at the Doua site. Different letters indicate significant differences between depths.

\begin{tabular}{ccccccc}
\hline Depth $(\mathrm{cm})$ & Sample size & BD_Min & BD_Mean & BD_Max & SWC_Min & SWC_Mean \\
\hline $0-10$ & 9 & 0.928 & $1.074 \mathrm{a}$ & 1.173 & 0.396 \\
$10-20$ & 3 & 1.046 & $1.090 \mathrm{a}$ & 1.168 & $0.433 \mathrm{a}$ & 0.272 \\
$20-30$ & 6 & 1.349 & $1.479 \mathrm{~b}$ & 1.648 & 0.278 & $0.300 \mathrm{~b}$ \\
$30-40$ & 3 & 1.587 & $1.658 \mathrm{bc}$ & 1.738 & 0.253 \\
$40-50$ & 3 & 1.677 & $1.716 \mathrm{c}$ & 1.763 & $0.267 \mathrm{~b}$ & 0.264 \\
\hline
\end{tabular}




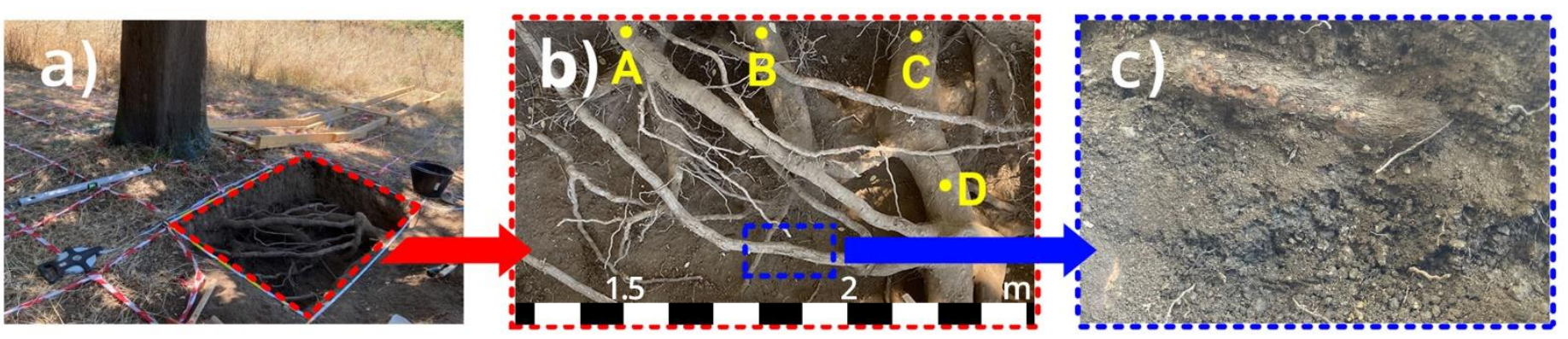

Fig. 3. (a-b): Trench excavated at the Berchidda site after the last GPR survey for detecting both root location and size and areas of infiltration and preferential pathways on the soil profile. (c): Patch of wetted soil. The red rectangles demarcate the position of the trench. The yellow dots demarcate the position of coarse roots. The blue area highlights the wetting zone. (For interpretation of the references to color in this figure legend, the reader is referred to the web version of this article.)

then applied to identify differences between layers (Table 1). Statistical analyses for bulk density, soil water content, and penetration resistance were computed using $\mathrm{R}$ ( $\mathrm{R}$ Core Team, 2020). The selected significance level for all tests was $\alpha=0.05$.

\subsubsection{Automated single-ring infiltration test}

The single-ring infiltration test carried out at the Doua site was aimed to provide evidence of lateral subsurface flow due to soil layering along with deeper preferential flow associated with shrub roots. The infiltration surface was established around the root system of a common barberry shrub (Berberis vulgaris L.) after severing its shoot. The automated single-ring infiltrometer proposed by Concialdi et al. (2020) (Fig. 2c) was used to infiltrate $280 \mathrm{~mm}$ of a shear-thinning viscous solution realized using $1 \mathrm{~g} \mathrm{~L}^{-1}$ of xanthan gum powder (Stewart et al., 2014). This solution was expected to fill preferential pathways due to the roots, with limited infiltration into the soil matrix, and thus reveal complex geometries or macropore networks (Abou Najm and Atallah, 2016; Atallah and Najm, 2019; Stewart et al., 2014). According to the Beerkan procedure, we inserted a stainless steel ring with a $15 \mathrm{~cm}$ inner diameter $1 \mathrm{~cm}$ into the soil as suggested by Lassabatere et al. (2006). The infiltrometer was positioned inside the ring and provided the xanthan gum solution at a constant pressure head. The height of the solution in the Mariotte reservoir was recorded using a differential transducer, which allowed the quantification of cumulative infiltration at the surface (Di Prima, 2015; Di Prima et al., 2016). A video showing the field setup and the data treatment is provided online (Di Prima, 2019).

\subsection{GPR data processing and solid modeling}

We processed each collected radargram (B-scan) using the Reflexw software version 4.0 (Sandmeier Scientific Software, Karlsruhe, Germany). The processing steps include: i) a trace interpolation for obtaining an equal distance between the marks taken along the survey line intersections with a marker increment of $0.2 \mathrm{~m}$ for the Doua site (otherwise, at the Berchidda site, the GPR data were collected using the wheel mode, and therefore they did not require a trace interpolation), ii) a static time shift to align direct ground wave arrival to $0 \mathrm{~ns}$, iii) a bandpass filtering within the time domain, iv) an exponential gain function to compensate GPR energy attenuation with propagation depth, v) a background removal filter for removing horizontal noise, and vi) a compression both in time- and in distance-directions to reduce the computational time needed for the subsequent processing step (i.e., 3D interpolation).

For each grid area, we created two datasets including i) the amplitude values and ii) the $\mathrm{X}, \mathrm{Y}$, and $\mathrm{Z}$ values representing location coordinates (easting, northing, and elevation) of all the pre- or post-wetting radargrams. The elevation, Z, was determined from the wave time, given by GPR acquisition and considering the value of wave velocity estimated from the detection of buried objects of known depths. More specifically, at the DOUA site, we buried a piece of metal to a known depth, $D$ (L), and measured the two-way travel time, $t(\mathrm{~T})$, in correspondence of the hyperbola vertex. We then calculated the
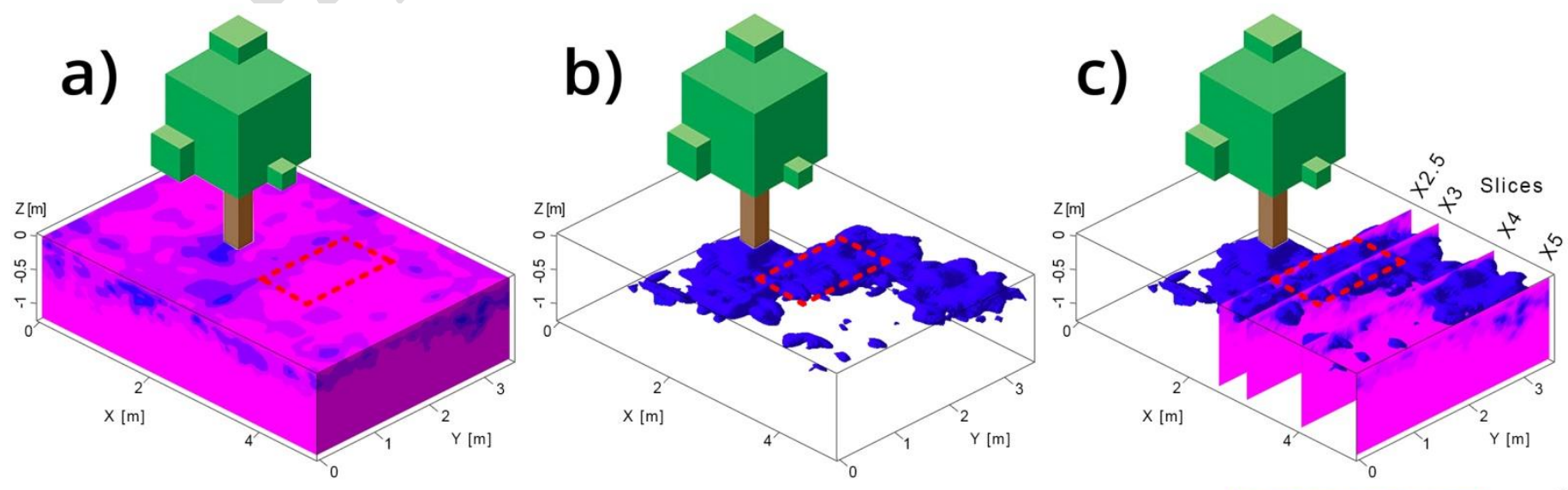

Absolute Difference

Fig 4. Diagrams obtained for the Berchidda site. (a): 3D diagram of the absolute difference between pre- and post-wetting amplitude values. (b): $3 \mathrm{D}$ representation of the wetting zones. (c): Procedure of slices extraction from the 3D diagram (see Fig. 5). The red rectangles demarcate the position of the trench (see Fig. 3). The clip art image of the tree illustrates the tree position with respect to spatial distribution of the wetting zone. (For interpretation of the references to color in this figure legend, the reader is referred to the web version of this article.) 

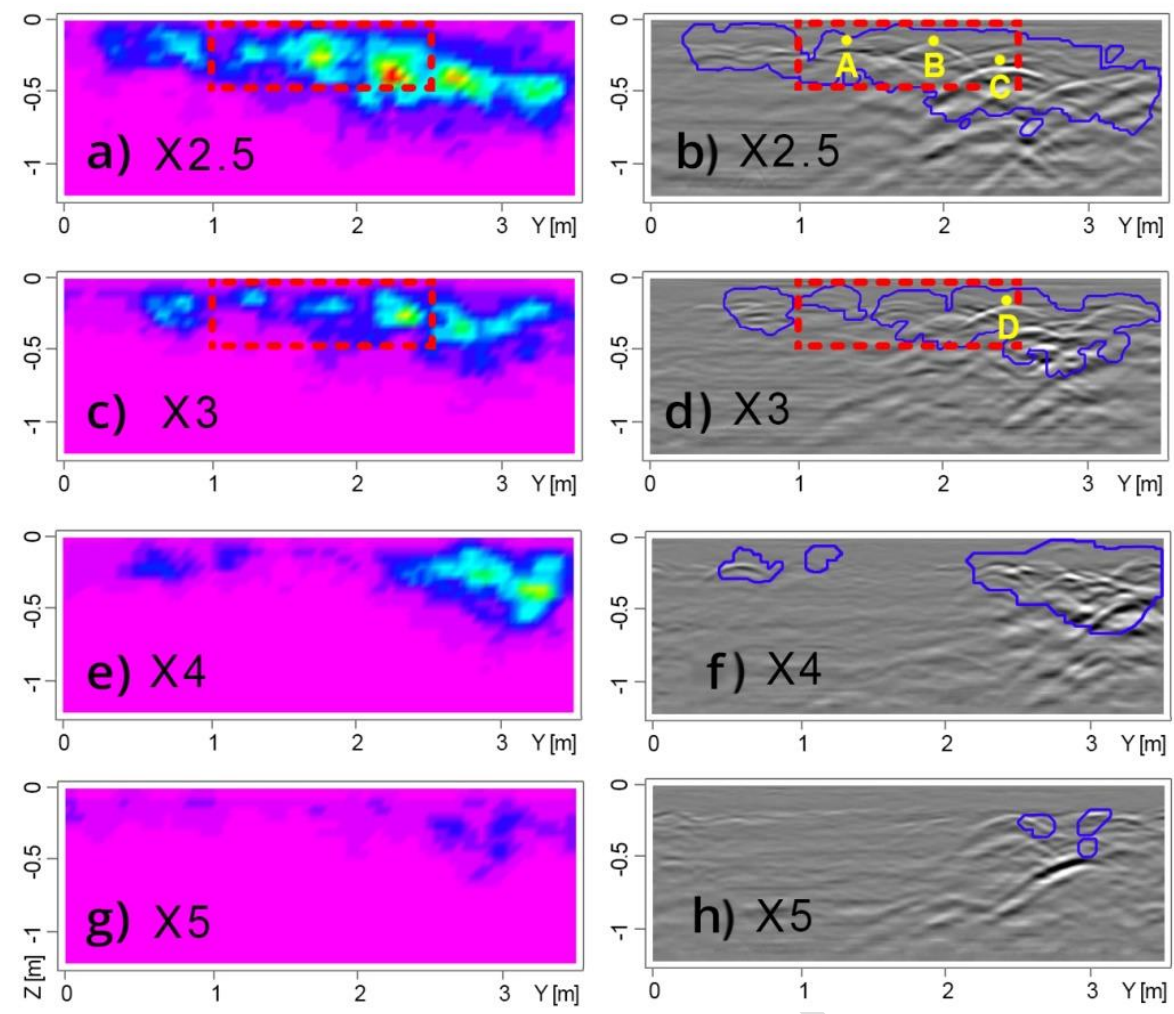

Fig. 5. (a), (c), (e), (g): Vertical slices extracted from the 3D diagram at different $X$ values (see Fig. 4c). (b), (d), (f), (h): Pre-wetting radargrams. The red rectangles demarcate the position of the trench excavated at the Berchidda site (see Fig. 3). The yellow dots demarcates the position of coarse roots. The blue areas on the radargrams highlight the wetting zones. (For interpretation of the references to color in this figure legend, the reader is referred to the web version of this article.)

wave velocity as $V=2 \times D / t$. At the Berchidda site, $V$ was calculated considering the coarse roots depth measured on the excavated trench. Coarse roots are manifested as reflection hyperbolas, because of the conical shape of the emitted radiowave signals. Indeed, when the antenna moved along a survey line approaching a root (target), the two-way travel time decreased towards its minimum value coinciding with the position of the antenna vertically above the target. Then, when antenna moved away from the target, the two-way travel time increased (Guo et al., 2013).

Next, we created differenced datasets based on absolute differences between pre- and post-wetting amplitude values. These datasets were realized to highlight the amplitude fluctuations between repeated GPR radargrams collected over the same survey lines before and after water infiltration (e.g., Guo et al., 2019; Holden, 2004). We used the RockWorks 17 software (RockWare, Inc., 2015) to perform a 3D interpolation of the differenced GPR datasets of the two sites and the penetration resistance data of the Doua site (Di Prima et al., 2020).

\section{Results}

\subsection{Evidence of stemflow-induced preferential flow paths along coarse roots: the Berchidda study}

\subsubsection{D representation of stemflow infiltration}

The results from the Berchidda study demonstrate the correspondence between the GPR signals and the presence of coarse roots detected on the excavated trench. For instance, the red rectangles demarcated in Figs. 3, 4 and 5 highlight the position of the trench on the corresponding survey lines X2.5 and $\mathrm{X} 3$. Within this zone, the pre-wetting radargram $\mathrm{X} 2.5$ shows three main reflection hyperbolas corresponding to three observed roots, having a diameter ranging from 0.085 to 0.115 $\mathrm{m}$ (yellow A-C dots in Figs. $3 \mathrm{~b}$ and $5 \mathrm{~b}$ ). The pre-wetting radargram $\mathrm{X} 3$ shows one main reflection hyperbola corresponding to an observed root with a diameter of $0.110 \mathrm{~m}$ (yellow D dot in Figs. 3b and 5d).

Fig. 4 illustrates the GPR determination of the wetted zones at the Berchidda site. The 3D diagram demarcates the dimension and shape of the wetted zone during the simulated stemflow event (Fig. 4b), which extended downslope up to a lateral distance of $3 \mathrm{~m}$ from the trunk (Fig. $5 \mathrm{~g}$ ) and down to a depth of approximately $0.7 \mathrm{~m}$ in the proximity of the tree (Fig. $5 a)$. The majority $(84.4 \%)$ of artificially applied stemflow infiltrated into the soil, while the remaining $15.6 \%$ generated overland flow (Fig. 1d). We firstly identified from the 360degree view of the 3D diagram zones that areas with strong reflection differences corresponded to patches of wetted soil. Yoriented vertical slices were extracted at $2.5,3,4$ and $5 \mathrm{~m}$ of the grid, corresponding to a distance of $0.5,1,2$ and $3 \mathrm{~m}$ from the tree trunk (Fig. 4c and 5a, c, e and g). Then, the wetted patterns demarcated on the slices were overlapped with the pre-wetting radargrams to identify the source of spatial heterogeneity that triggered preferential flow (blue demarcated zones in Figs. 5b, $\mathrm{d}, \mathrm{f}$ and $\mathrm{h}$ ). The wetted patterns closely matched the reflection hyperbolas and the direct observation of dyed patterns (e.g., blue arrow in Figs. $3 \mathrm{~b}-\mathrm{c}$ ), thereby providing evidence of rootinduced preferential flow along coarse roots, and validating the applied protocol. This result constitutes an encouraging signal of the validity of the $3 \mathrm{D}$ interpolation procedure to determine the wetted patterns, and also serves as an experimental confirmation of a previous investigation carried out by Di Prima et al. (2020). 


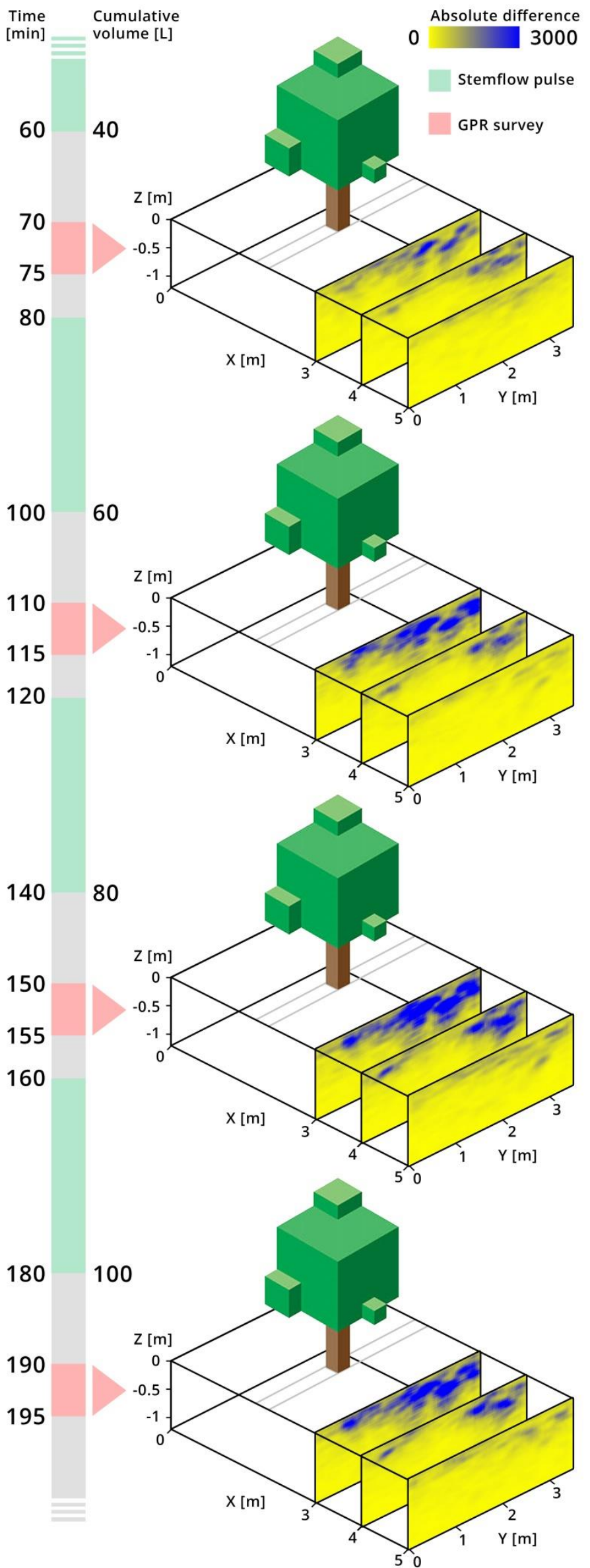

Fig. 6. Differenced radargrams collected at 3, 4 and $5 \mathrm{~m}$ of the grid after 70, 110, 150 and $190 \mathrm{~min}$ from the beginning of the stemflow simulation event carried out at the Berchidda site (see Fig. 1). The applied cumulative stemflow volume is also reported on the timeline. The clip art image of the tree illustrates the tree position with respect to survey lines.

\subsubsection{Real-time monitoring and interpretation of subsurface flow process along coarse roots}

The GPR surveys carried out during the artificial stemflow experiment provided real-time monitoring of subsurface flow process along coarse roots. Fig. 6 shows reflection changes that occurred during the experiments on the survey lines X3, X4 and $X 5$. We did not measure a substantial reflection change on the X5 survey line $70 \mathrm{~min}$ after infiltration started, i.e., after the first two stemflow pulses. Here, a moderate increase in signal amplitude appeared only after $110 \mathrm{~min}$ at approximate depths of 20 and $40 \mathrm{~cm}$, indicating the wetting zone extended beyond the downhill border of the grid. The amplitude changes were mainly distributed on three patches coinciding with three reflection hyperbolas (Fig. 5h), revealing the important role of coarse roots in facilitating preferential water movement far from the tree trunk through the subsurface.

Otherwise, we measured strong reflection changes on the $\mathrm{X} 3$ and X4 survey lines $70 \mathrm{~min}$ after infiltration started. Here, the signal amplitude increased until achieving maximum differences between pre- and post-wetting conditions after the fourth stemflow pulse, i.e., $150 \mathrm{~min}$ after infiltration started. Between the fourth (150 min after the beginning of the artificial stemflow experiment) and fifth (190 min) GPR survey, no substantial differences were observed on the wetted pattern shapes, signaling that the partially saturated (transmission) zone that surrounded the fast-flow region achieved its maximum extension. In this zone, the water pressure head decreased as the wetting front moved away due to soil capillarity and imbibition of water from preferential paths (Lassabatere et al., 2019, 2014). Thus, although water mainly moved along preferential flow paths, infiltrated water also moved outward from stems due to water exchange between preferential flow pathways and matrix regions.

\subsubsection{On the hydrological relevance of stemflow- induced infiltration}

Many previous investigations have highlighted the hydrological importance of stemflow (e.g., Van Stan and Allen, 2020), and most of stemflow experiments have used dye tracers to identify stemflow infiltration (Gonzalez-Ollauri et al., 2020; Schwärzel et al., 2012; Spencer and van Meerveld, 2016). Those experiments require extensive effort to quantify wetting patterns, as an adequate observation of deep dye patterns requires sectioning the soil along different vertical or horizontal planes. These procedures are destructive to the soil.

In this investigation, we, for the first time, determined a 3D representation of the entire wetted zone generated during a stemflow simulation. The adopted protocol and the 3D observation of the wetted zones provide empirical evidence of the so-called "double-funneling" effect, in which stemflow is first concentrated from the canopy to the stems, and then once belowground becomes funneled by tree roots (Johnson and Lehmann, 2006). Specifically, the time-lapse radargrams measured in this study show that the root network promoted lateral subsurface flow. While previous work has indicated that hillslope response to rainstorms can be controlled by the presence of a subsurface lateral preferential flow network (Bachmair and Weiler, 2011; Guo et al., 2019), this hydrological process has not yet been studied in Mediterranean woodlands with scattered trees. 

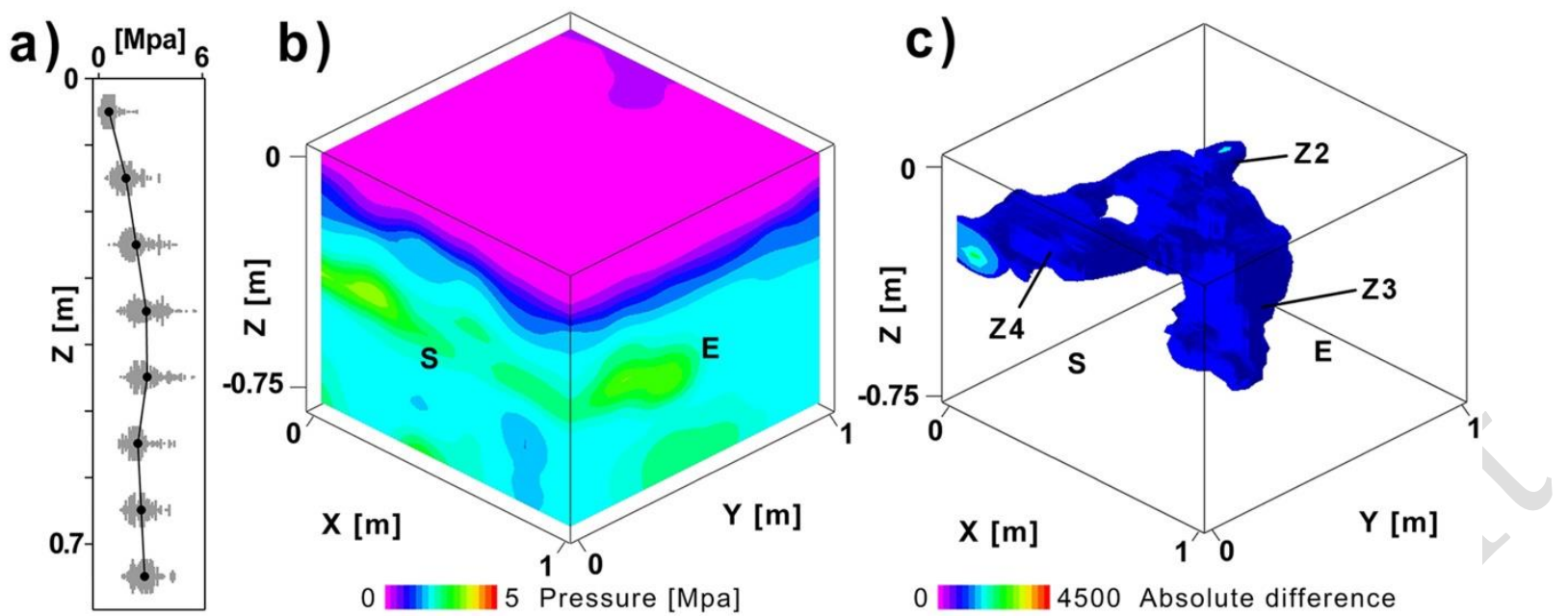

Fig. 7. (a): Plot of the 3D diagrams of the resistance penetrometer data. 3D diagrams of the (b) resistance penetrometer measurements and (c) wetting zone from pre- and post-wetting ground-penetrating radar surveys (see Fig. 2) at the Doua site.

In this type of environment, we expect the presence of spatially disconnected zones where lateral subsurface flow is boosted in the immediate vicinity of the trees by stemflowinduced infiltration, which flows preferentially along roots (Schwärzel et al., 2012). This process strongly affects hydrologic and nutrient fluxes leading to highly heterogeneous soil water dynamics. As a consequence, the tree density and the degree of connectivity between these isolated hydrologically active areas are expected to play an important role in controlling hillslope response to rainstorms. Future research carried out at the Berchidda site or similar ecosystems should seek to address the role that the scattered trees play on ecohydrological processes and water dynamics also at a larger scale (e.g., hillslope scale). To this aim, the applied protocol, in conjunction with the monitoring of the precipitation partition into interception, stemflow and throughfall, will allow researchers to gain more comprehensive understanding of the ecohydrological role played by scattered trees in Mediterranean agro-silvo-pastoral systems.

\subsection{Water infiltration into a layered soil: the Doua study case}

\subsubsection{Detection of soil layers and wetting zones through penetration resistance readings}

To check the capacity of penetration resistance surveys to detect different soil horizons, we obtained a 3D diagram of penetration resistance values for the sampled grid at the Doua site (Fig. 7b). The horizontal and vertical slices demarcate differences in penetration resistance along the soil profile (Fig. $8 \mathrm{~g}-\mathrm{i})$. For the first $0.2 \mathrm{~m}$, the mean penetration resistance was less than 1.6 MPa. Mean penetration resistance then increased until reaching $2.9 \mathrm{MPa}$ at a depth between 0.3 and $0.5 \mathrm{~m}$, before decreasing slightly at depths greater than $0.5 \mathrm{~m}$ (Fig. 7a). To check if this difference was statistically relevant, penetration resistance data were grouped by eight depth increments (i.e., every $0.1 \mathrm{~m}$ from 0 to $0.8 \mathrm{~m}$ ). Both non-transformed and logtransformed penetration resistance data were non-normally distributed according to the Shapiro-Wilk test. Thus, we applied a non-parametric Kruskal-Wallis test to determine whether any of the differences between the medians were statistically significant, followed by pairwise comparisons using Wilcoxon rank sum test. The test results (Table 2) confirm statistically significant differences $(P<0.05)$ between every depth in the first $0.4 \mathrm{~m}$ of the soil profile, with the highest resistance detected between 0.3 and $0.5 \mathrm{~m}$ depths.

As further confirmation that penetration resistance readings effectively detected soil layering, the soil bulk density was significantly lower in the upper $0.2 \mathrm{~m}\left(1.09 \mathrm{~g} \mathrm{~cm}^{-3}\right)$ compared to deeper soil layers ( $\geq 1.48 \mathrm{~g} \mathrm{~cm}^{-3}$; Table 1$)$. Moreover, soil layering was also identifiable by visual observation of the soil cores. In addition, the initial soil water content along the soil profile was substantially higher in the upper $0.1 \mathrm{~m}$, and did not vary within deeper layers (Table 1 ). The homogeneity of the initial soil water content between 0.2 and $0.5 \mathrm{~m}$ allowed us to exclude possible misinterpretations of penetration resistance due to moisture variation, since it is known that this quantity exhibits an inverse relationship with soil water content, with minimal friction between the soil and the metal probe for high water contents (Vaz et al., 2011).

Both the vertical (Figs. 8a and c) and horizontal (Fig. 8b) slices extracted from the $3 \mathrm{D}$ diagram show lower penetration resistance values corresponding to the wetting zone (demarcated zones $\mathrm{Z1}$ in Figs. $8 \mathrm{a}-\mathrm{c}$ ), due to the above cited inverse relationship between penetration resistance and soil water content. In this case, we created two datasets of penetration resistance data. The first dataset included the four penetration resistance profiles located at the corners of the grid, where the penetration occurred on apparently dry zones. The second dataset included other four penetration resistance profiles located at the center of the grid, where the cone of the probe penetrated the wet soil. The two datasets had median values of $1.8 \mathrm{MPa}$ (wet soil at the center of the grid) versus 2.1

Table 2. Results of the non-parametric Kruskal-Wallis test for the eight groups of the penetration resistance $(\mathrm{MPa})$ values. Different letters indicate significant differences between depths $(\alpha=0.05)$.

\begin{tabular}{cccccc}
\hline Depth [m] & Sample size & Median & Min & Mean & Max \\
\hline $0.0-0.1$ & 354 & 0.6 & 0.32 & $0.63 \mathrm{a}$ & 1.00 \\
$0.1-0.2$ & 360 & 1.5 & 0.97 & $1.60 \mathrm{~b}$ & 2.71 \\
$0.2-0.3$ & 357 & 2.0 & 1.37 & $2.17 \mathrm{c}$ & 3.89 \\
$0.3-0.4$ & 360 & 2.7 & 1.32 & $2.78 \mathrm{~d}$ & 4.73 \\
$0.4-0.5$ & 351 & 2.6 & 1.83 & $2.87 \mathrm{~d}$ & 4.81 \\
$0.5-0.6$ & 350 & 2.2 & 1.37 & $2.25 \mathrm{c}$ & 3.94 \\
$0.6-0.7$ & 350 & 2.5 & 1.53 & $2.46 \mathrm{~cd}$ & 4.07 \\
$0.7-0.8$ & 385 & 2.7 & 1.70 & $2.66 \mathrm{~d}$ & 4.30 \\
Overall & 2867 & 2.2 & 0.32 & 2.17 & 4.81 \\
\hline
\end{tabular}



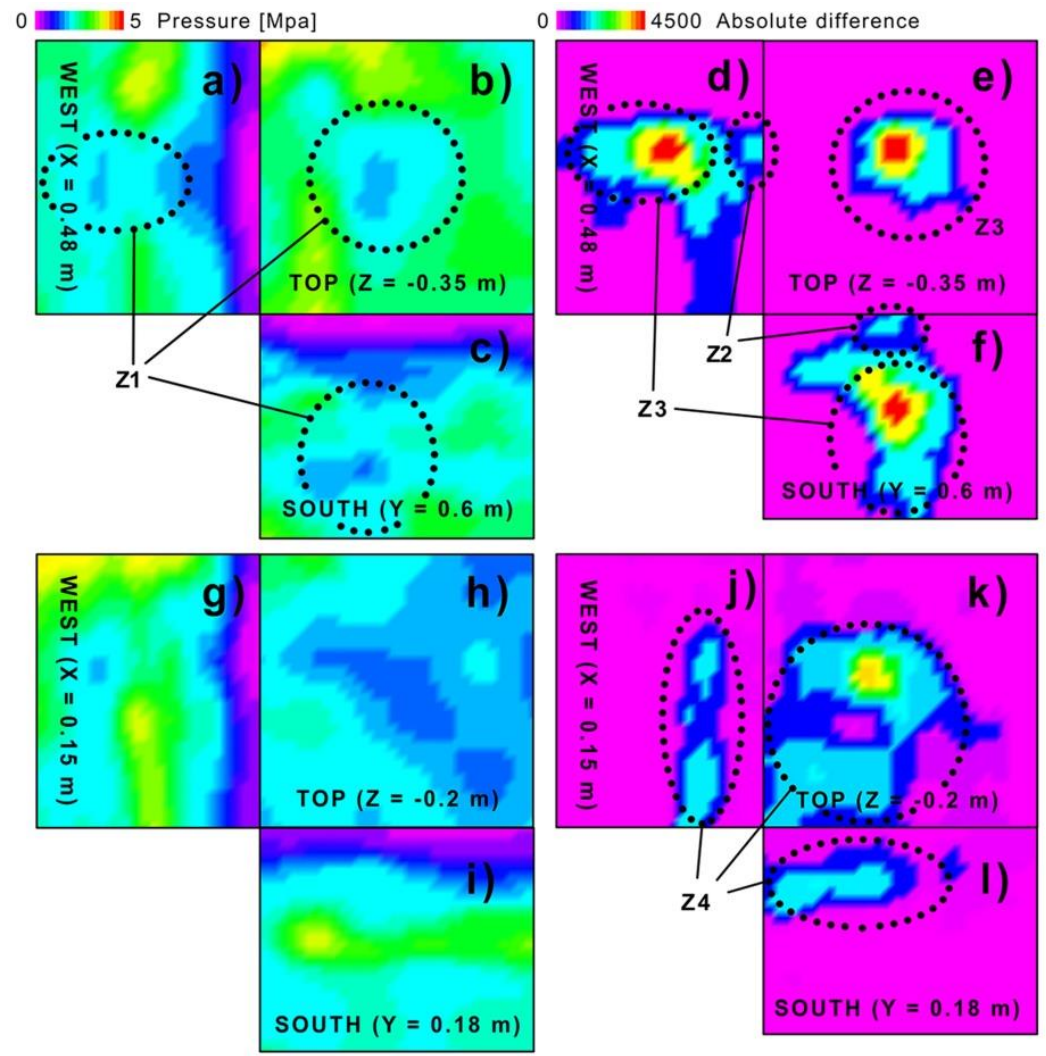

Fig. 8. (b), (e), (h), (k): Horizontal slices extracted from the 3D diagrams (see Figure 7) of the penetration resistance (left) and infiltration bulb (right) at different depths from the soil surface. (a), (d), (g), (j): North-south oriented (west view) and (c), (f), (i), (l): West-east oriented (south view) vertical slices. The areas demarcated with dotted black lines (Z1, Z2, Z3 and Z4) highlight specific wetting zones.

MPa (dry soil at the corners of the grid), with statistically significant differences between medians according to the Kruskal-Wallis test $(P<0.05)$. More specifically, zones with lower penetration resistance values, corresponding to the wetted soil, were also detected through the restrictive layer at a depth between 0.5 and $0.6 \mathrm{~m}$ in correspondence of the shrub plant root system (Figs. 8a and c).

Penetration resistance data had a double valuable outcome. Indeed, the 3D penetration resistance diagram provided us an accurate description of soil layering and, at the same time, it provided a rough information on the expansion of the wetting zone in the subsurface.

\subsubsection{Detection of lateral flow and preferential flow pathways into a layered soil through GPR data}

At the Doua site the use of time-lapse GPR surveys allowed us to resolve water perching above a shallow restrictive layer. Fig. 7c shows the 3D diagram of the wetted zone created during the infiltration experiment. The 3D diagram shows an elongated shape within the first $0.2 \mathrm{~m}$ of soil, indicating that water moved rapidly in this zone following the plant root system (demarcated zones Z2 in Figs. 7c, 8d and f). When water arrived to the interface between layers (0.2 $\mathrm{m}$ depth), the dense layer impeded water flow. There the flow diverged, with some water moving laterally in the southwest direction (demarcated zones $\mathrm{Z} 4$ in Figs. $7 \mathrm{C}$ and $8 \mathrm{j}-1$ ), and the remaining water infiltrating into the dense layer via preferential flow paths that appear to correspond to the plant root system (demarcated zones Z3 in Figs. $7 \mathrm{c}$ and $8 \mathrm{~d}-\mathrm{f}$ ). These observations are in line with a previous investigation carried out at the Doua site by Di Prima et al. (2020) at another point. Indeed, those authors reported preferential flow pathways within the underlying layer associated with plant roots. However, where the previous procedure required those authors to expose the dyed patterns by excavating the soil at the end of the experiment, here we supported the interpretation of GPR data with a nondestructive method, i.e., 3D penetration resistance measurements, which allowed us to detect soil layering and also the portions of wetted soils, by minimizing soil disturbance.

The GPR and penetration resistance data therefore both indicated that water infiltrated through the restrictive layer mainly following the plant root system, revealing that roots act as important flow pathways at the studied site. At the same time, the observed flow accumulation along the layer interface suggests that the studied soil may be prone to a saturationexcess overland flow mechanism (Biddoccu et al., 2017). Indeed, while the sparse shrubs locally boost water infiltration, in case of extreme rainfall events, percolating water may accumulate above the restrictive layer and form a shallow perched water table that could rise, causing the complete saturation of the upper soil profile (Stewart et al., 2019).

\section{Summary and conclusions}

In this study, we combined time-lapse GPR surveys with different types of infiltration tests to improve understanding of the water infiltration dynamics in the subsurface. The timelapse GPR surveys allowed us to create 3D diagrams of the wetted zones, which enhanced the visualization and interpretation of the infiltration patterns. At both experimental sites, the 3D diagrams were verified by in situ observations, independent measurement and field excavations. Indeed, the proposed approach offers a non-invasive (or minimally invasive), repeatable, and accurate way to detect non-uniform 
flow. It therefore constitutes a valid alternative technique to the traditional methods for investigating the linkages between heterogeneous soil and non-uniform flow.

By coupling time-lapse GPR surveys and infiltration experiments, this study revealed links between different types of soil heterogeneity and non-uniform flow. The results allowed us to quantify how root systems play an important role in channeling soil water both in the horizontal and vertical directions. Moreover, this study, for the first time, led to the creation of a 3D representation of the entire wetted zone generated during an artificial stemflow infiltration event by real-time monitoring of subsurface flow process. This finding provides empirical evidence of the double-funneling effect - in which roots are thought to cause the rapid movement of stemflow through the subsurface - and shows that root networks can promote extensive lateral subsurface flow.

The obtained results also highlight the potential of 3D GPR imaging to be utilized for calibrating and verifying numerical simulations. For instance, by visualizing wetting patterns from stemflow using real-time GPR monitoring, modeling scenarios can be developed that accurately simulate the role of coarse roots in facilitating preferential water movement. Altogether, coupling time-lapse GPR surveys and infiltration experiments offers the possibility of obtaining a more comprehensive overview of the ecohydrological role played by vegetation. We therefore recommend that such techniques should be applied in future research on plant-soil-water interactions.

\section{CRediT authorship contribution statement}

Simone Di Prima: Conceptualization, Methodology, Investigation, Formal analysis, Validation, Visualization, Writing - original draft, Writing - Review \& Editing, Funding acquisition. Vittoria Giannini: Investigation, Writing - Review \& Editing. Ludmila Ribeiro Roder: Investigation, Data Curation, Writing - original draft, Writing - Review \& Editing. Filippo Giadrossich: Investigation, Writing - Review \& Editing. Laurent Lassabatere: Writing - Review \& Editing, Funding acquisition. Ryan D. Stewart: Writing - Review \& Editing. Majdi R. Abou Najm: Writing - Review \& Editing. Vittorio Longo: Writing - Review \& Editing. Sergio Campus: Investigation. Thierry Winiarski: Writing - Review \& Editing. Rafael Angulo-Jaramillo: Writing - Review \& Editing. Antonio del Campo: Writing - Review \& Editing. Giorgio Capello: Investigation, Writing - Review \& Editing. Marcella Biddoccu: Writing - Review \& Editing, Funding acquisition. Pier Paolo Roggero: Writing - Review \& Editing, Funding acquisition. Mario Pirastru: Writing - Review \& Editing.

\section{Funding}

This work was supported through i) the European Regional Development Fund (ERDF) and the Italian Ministry of Education, University and Research (MIUR) through the "Programma Operativo Nazionale (PON) Ricerca e Innovazione 2014-2020 (Linea 1 - Mobilità dei ricercatori, AIM1853149, CUP: J54I18000120001), ii) GASPAM Gestione Agronomica Sostenibile dei Pascoli Arborati Mediterranei. Regione Sardegna, L. 7/2007, 2019-21, iii) the INFILTRON Project (ANR17-CE04-0010, Package for assessing infiltration \& filtration functions of urban soils in stormwater management; https://infiltron.org/), iv) the Short Term Mobility (STM) Program 2019 of CNR (Research Programme: “Innovative techniques for hydraulic characterization of soil"), and v) the "fondo di Ateneo per la ricerca 2020" of the University of Sassari.

\section{Conflicts of interest}

The authors declare that they have no known competing financial interests or personal relationships that could have appeared to influence the work reported in this paper.

\section{Acknowledgements}

The authors thank Sara Puijalon and the Lyon city Field Observatory for UrbanWater Management (OTHU), for technical and scientific support. S.D.P. also thanks Nicolò, Alex and Steve for their contribution to keep the spirit up.

\section{References}

Abou Najm, M., Lassabatere, L., Stewart, R.D., 2019. Current Insights into Nonuniform Flow across Scales, Processes, and Applications. Vadose Zone Journal 18. https://doi.org/10.2136/vzj2019.10.0113

Abou Najm, M.R., Atallah, N.M., 2016. Non-Newtonian Fluids in Action: Revisiting Hydraulic Conductivity and Pore Size Distribution of Porous Media. Vadose Zone Journal 15, 0. https://doi.org/10.2136/vzj2015.06.0092

Abou Najm, M.R., Jalal D. Jabro, William M. Iversen, Rabi H. Mohtar, Robert G. Evans, 2010. New method for the characterization of three-dimensional preferential flow path in the field. Water Resources Research 46. https://doi.org/10.1029/2009WR008594

Allroggen, N., van Schaik, N.L.M.B., Tronicke, J., 2015. 4D ground-penetrating radar during a plot scale dye tracer experiment. Journal of Applied Geophysics 118, 139-144. https://doi.org/10.1016/j.jappgeo.2015.04.016

Angulo-Jaramillo, R., Bagarello, V., Iovino, M., Lassabatère, L., 2016. Infiltration Measurements for Soil Hydraulic Characterization. Springer International Publishing. Atallah, N.M., Abou Najm, M.R., 2019. Characterization of synthetic porous media using non-Newtonian fluids: experimental evidence. European Journal of Soil Science 70, 257-267. https://doi.org/10.1111/ejss.12746

Bacchetta, G., Bagella, S., Biondi, E., Farris, E., Filigheddu, R., Mossa, L., 2004. A contribution to the knowledge of the order Quercetalia ilicis Br.-Bl. ex Molinier 1934 of Sardinia. Fitosociologia 41(1), 29-51.

Bachmair, S., Weiler, M., 2011. New Dimensions of Hillslope Hydrology, in: Levia, D.F., Carlyle-Moses, D., Tanaka, T. (Eds.), Forest Hydrology and Biogeochemistry,

Ecological Studies. Springer Netherlands, Dordrecht, pp. 455-481.

https://doi.org/10.1007/978-94-007-1363-5_23

Basset, C.N., Najm, M.R.A., Ammar, A., Stewart, R.D., Hauswirth, S.C., Saad, G., 2019. Physically Based Model for Extracting Dual-Permeability Parameters Using NonNewtonian Fluids. Vadose Zone Journal 18, 180172

https://doi.org/10.2136/vzj2018.09.0172

Ben Slimene, E., Lassabatere, L., Šimůnek, J., Winiarski, T., Gourdon, R., 2017. The role of heterogeneous lithology in a glaciofluvial deposit on unsaturated preferential flow - a numerical study. Journal of Hydrology and Hydromechanics 65, 209-221.

https://doi.org/10.1515/johh-2017-0004

Biddoccu, M., Ferraris, S., Pitacco, A., Cavallo, E., 2017. Temporal variability of soil management effects on soil hydrological properties, runoff and erosion at the field scale in a hillslope vineyard, North-West Italy. Soil and Tillage Research 165, 46-58. https://doi.org/10.1016/j.still.2016.07.017

Birken, R., Versteeg, R., 2000. Use of four-dimensional ground penetrating radar and advanced visualization methods to determine subsurface fluid migration. Journal of Applied Geophysics 43, 215-226. https://doi.org/10.1016/S0926-9851(99)00060-9 Concialdi, P., Di Prima, S., Bhanderi, H.M., Stewart, R.D., Abou Najm, M.R., Lal Gaur, M., Angulo-Jaramillo, R., Lassabatere, L., 2020. An open-source instrumentation package for intensive soil hydraulic characterization. Journal of Hydrology 582. https://doi.org/10.1016/j.jhydrol.2019.124492

de Almeida, A.P., Riekerk, H., 1990. Water balance of Eucalyptus globulus and Quercus suber forest stands in south Portugal. Forest Ecology and Management 38, 55-64. https://doi.org/10.1016/0378-1127(90)90085-P

Di Prima, S., 2019. An open source instrumentation package for intensive soil hydraulic characterization [https://www.youtube.com/watch?v=KW1zLcuDQg8].

Di Prima, S., 2015. Automated single ring infiltrometer with a low-cost microcontroller circuit. Computers and Electronics in Agriculture 118, 390-395.

https://doi.org/10.1016/j.compag.2015.09.022

Di Prima, S., Lassabatere, L., Bagarello, V., Iovino, M., Angulo-Jaramillo, R., 2016. Testing a new automated single ring infiltrometer for Beerkan infiltration experiments. Geoderma 262, 20-34. https://doi.org/10.1016/j.geoderma.2015.08.006

Di Prima, S., Winiarski, T., Angulo-Jaramillo, R., Stewart, R.D., Castellini, M., Abou Najm, M.R., Ventrella, D., Pirastru, M., Giadrossich, F., Capello, G., Biddoccu, M., Lassabatere, L., 2020. Detecting infiltrated water and preferential flow pathways through time-lapse ground-penetrating radar surveys. Science of The Total Environment 138511. https://doi.org/10.1016/j.scitotenv.2020.138511

Fan, B., Liu, X., Zhu, Q., Qin, G., Li, J., Lin, H., Guo, L., 2020. Exploring the interplay between infiltration dynamics and Critical Zone structures with multiscale geophysical imaging: A review. Geoderma 374, 114431.

https://doi.org/10.1016/j.geoderma.2020.114431

Gerke, H.H., 2006. Preferential flow descriptions for structured soils. Journal of Plant Nutrition and Soil Science 169, 382-400. https://doi.org/10.1002/jpln.200521955 Gerke, K.M., Sidle, R.C., Mallants, D., 2015. Preferential flow mechanisms identified from staining experiments in forested hillslopes: Preferential Flow Mechanisms 
Identified from Staining Experiments. Hydrological Processes 29, 4562-4578. https://doi.org/10.1002/hyp.10468

Gonzalez-Ollauri, A., Stokes, A., Mickovski, S.B., 2020. A novel framework to study the effect of tree architectural traits on stemflow yield and its consequences for soil-water dynamics. Journal of Hydrology 582, 124448 .

https://doi.org/10.1016/j.jhydrol.2019.124448

Gormally, K.H., McIntosh, M.S., Mucciardi, A.N., McCarty, G.W., 2011. GroundPenetrating Radar Detection and Three-Dimensional Mapping of Lateral Macropores: II Riparian Application. Soil Science Society of America Journal 75, 1236. https://doi.org/10.2136/sssaj2010.0342

Guo, L., Chen, J., Cui, X., Fan, B., Lin, H., 2013. Application of ground penetrating radar for coarse root detection and quantification: a review. Plant Soil 362, 1-23. https://doi.org/10.1007/s11104-012-1455-5

Guo, L., Lin, H., Fan, B., Nyquist, J., Toran, L., Mount, G.J., 2019. Preferential flow through shallow fractured bedrock and a 3D fill-and-spill model of hillslope subsurface hydrology. Journal of Hydrology 576, 430-442.

https://doi.org/10.1016/j.jhydrol.2019.06.070

Guo, L., Mount, G.J., Hudson, S., Lin, H., Levia, D., 2020. Pairing geophysical techniques improves understanding of the near-surface Critical Zone: Visualization of preferential routing of stemflow along coarse roots. Geoderma 357, 113953.

https://doi.org/10.1016/j.geoderma.2019.113953

Hauswirth, S.C., Najm, M.R.A., Miller, C.T., 2019. Characterization of the Pore Structure of Porous Media Using non-Newtonian Fluids. Water Resources Research 55, 71827195. https://doi.org/10.1029/2019WR025044

Holden, J., 2004. Hydrological connectivity of soil pipes determined by groundpenetrating radar tracer detection. Earth Surface Processes and Landforms 29, 437-442. https://doi.org/10.1002/esp.1039

Johnson, M.S., Lehmann, J., 2006. Double-funneling of trees: Stemflow and root-induced preferential flow. Écoscience 13, 324-333. https://doi.org/10.2980/i1195-6860-13-3324.1

Kodešová, R., Němeček, K., Kodeš, V., Žigová, A., 2012. Using Dye Tracer for Visualization of Preferential Flow at Macro- and Microscales. Vadose Zone Journal 11, 0. https://doi.org/10.2136/vzj2011.0088

Lassabatere, L., Angulo-Jaramillo, R., Soria Ugalde, J.M., Cuenca, R., Braud, I., Haverkamp, R., 2006. Beerkan estimation of soil transfer parameters through infiltration experiments-BEST. Soil Science Society of America Journal 70, 521. https://doi.org/10.2136/sssaj2005.0026

Lassabatere, L., Di Prima, S., Bouarafa, S., Iovino, M., Bagarello, V., Angulo-Jaramillo, R., 2019. BEST-2K Method for Characterizing Dual-Permeability Unsaturated Soils with Ponded and Tension Infiltrometers. Vadose Zone Journal 18 https://doi.org/10.2136/vzj2018.06.0124
Lassabatere, L., Yilmaz, D., Peyrard, X., Peyneau, P.E., Lenoir, T., Šimůnek, J., AnguloJaramillo, R., 2014. New Analytical Model for Cumulative Infiltration into DualPermeability Soils. Vadose Zone Journal 0, 0. https://doi.org/10.2136/vzj2013.10.0181

Lozano-Parra, J., Schnabel, S., Ceballos-Barbancho, A., 2015. The role of vegetation covers on soil wetting processes at rainfall event scale in scattered tree woodland of Mediterranean climate. Journal of Hydrology 529, 951-961.

https://doi.org/10.1016/j.jhydrol.2015.09.018

RockWare, Inc., 2015. RockWorks17 User's Manual [WWW Document]. URL https://www.rockware.com/downloads/documentation/rockworks/rockworks17.pdf (accessed 8.8.19).

Schwärzel, K., Ebermann, S., Schalling, N., 2012. Evidence of double-funneling effect of beech trees by visualization of flow pathways using dye tracer. Journal of Hydrology 470-471, 184-192. https://doi.org/10.1016/j.jhydrol.2012.08.048

Seddaiu, G., Bagella, S., Pulina, A., Cappai, C., Salis, L., Rossetti, I., Lai, R., Roggero, P.P., 2018. Mediterranean cork oak wooded grasslands: synergies and trade-offs between plant diversity, pasture production and soil carbon. Agroforest Syst 92, 893-908. https://doi.org/10.1007/s10457-018-0225-7

Spencer, S.A., van Meerveld, H.J. van, 2016. Double funnelling in a mature coastal British Columbia forest: spatial patterns of stemflow after infiltration. Hydrological Processes 30, 4185-4201. https://doi.org/10.1002/hyp.10936

Stewart, R.D., Bhaskar, A.S., Parolari, A.J., Herrmann, D.L., Jian, J., Schifman, L.A., Shuster, W.D., 2019. An analytical approach to ascertain saturation-excess versus infiltration-excess overland flow in urban and reference landscapes. Hydrological Processes 33, 3349-3363. https://doi.org/10.1002/hyp.13562

Stewart, R.D., Najm, M.R.A., Rupp, D.E., Selker, J.S., 2014. Nondestructive Quantification of Macropore Volume using Shear-Thinning Fluid. Soil Science Society of America Journal 78, 445-453. https://doi.org/10.2136/sssaj2013.08.0346

Truss, S., Grasmueck, M., Vega, S., Viggiano, D.A., 2007. Imaging rainfall drainage within the Miami oolitic limestone using high-resolution time-lapse ground-penetrating radar: IMAGING DRAINAGE USING TIME-LAPSE GPR. Water Resour. Res. 43. https://doi.org/10.1029/2005WR004395

Van Stan, J.T., Allen, S.T., 2020. What We Know About Stemflow's Infiltration Area. Front. For. Glob. Change 3, 61. https://doi.org/10.3389/ffgc.2020.00061

Vaz, C.M.P., Manieri, J.M., de Maria, I.C., Tuller, M., 2011. Modeling and correction of soil penetration resistance for varying soil water content. Geoderma 166, 92-101. https://doi.org/10.1016/j.geoderma.2011.07.016

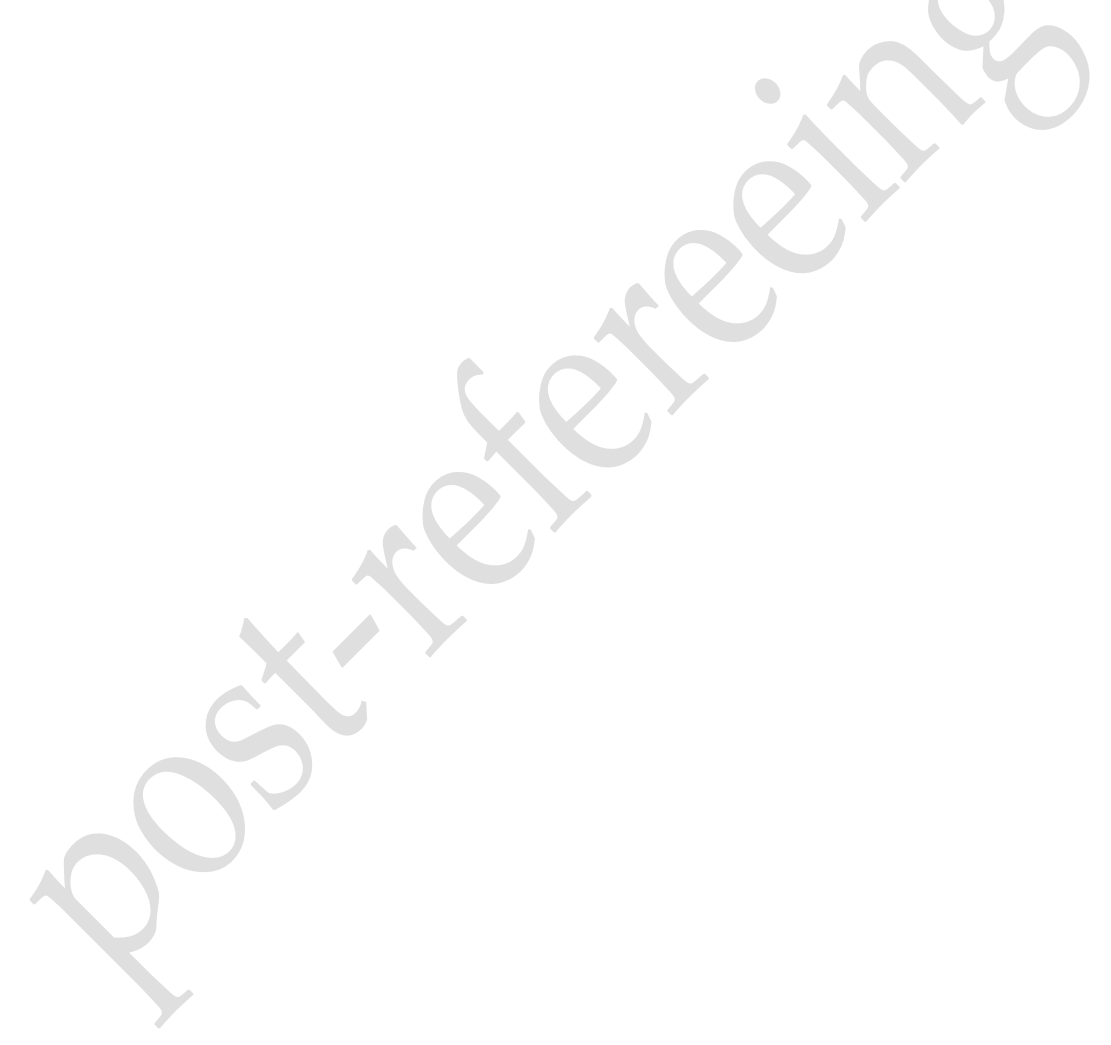

